\title{
Qualitative and Quantitative Estimation of Guggulsterone E and Z in Different Sodhit Guggul by LC-MS and HPLC Method
}

\author{
Patel Mayuree ${ }^{1,2}$, Macwan Carol ${ }^{2}$, B. N. Suhagia ${ }^{3}$ and Sanjeev R. Acharya ${ }^{4,5 *}$ \\ 'Institute of Pharmacy, Nirma University, S. G. Highway, Ahmedabad - 382481, Gujarat, India \\ ${ }^{2}$ Department of Pharmacognosy, Faculty of Pharmacy, Dharmsinh Desai University, \\ College Road, Nadiad - 387001, Gujarat, India \\ ${ }^{3}$ Department of Pharmaceutical Chemistry, Faculty of Pharmacy, Dharmsinh Desai University, College Road, \\ Nadiad - 387001, Gujarat, India \\ ${ }^{4}$ S. S. R. College of Pharmacy (Affiliated to Savitribai Phule Pune University, Pune), Sayli,-Silvassa - 396230, \\ Maharashtra, India \\ ${ }^{5}$ Department of Pharmacognosy, Institute of Pharmacy, Nirma University, S. G. Highway, \\ Ahmedabad - 382481, Gujarat, India; \\ sanjeevracharya@gmail.com
}

\begin{abstract}
Objective: Guggul is the oleo-gum-resin obtained from deep incisions at the basal part of stem bark of Commiphora wightii belonging to Burseraceae family. It is very popular ancient Ayurvedic medicine used to cure various diseases. In Ayurveda guggul is always purified prior to use in different formulations. This process is known as sodhana. Guggulsterone $E$ and $Z$ are the prime constituents of Commiphora wightii. The main objective of this study was to identify the impact of guggul sodhana process mentioned in Ayurvedic Formulary of India (AFI) on the content of guggulsterone $\mathrm{E}$ and $\mathrm{Z}$. The methanol extract of raw guggul and seven different sodhit guggul were qualitatively and quantitatively analysed by using LC-MS and HPLC methods. The LC-MS specrum indicated the presence of guggulsterone E\&Z at $\mathrm{m} / \mathrm{z}-313.2$ in all samples with a retention time $4.8 \mathrm{~min}$ and $5.7 \mathrm{~min}$ respectively. The HPLC chromatogram at $245 \mathrm{~nm}$ showed guggulsterone E \& $Z$ with same retention time in all samples. The study reports that all the sodhit guggul samples contain guggulsterone E\&Z. The water shodhit guggul showed $95.95 \%$ of total guggulsterone while triphala shodhit guggul showed $74.21 \%$. It is suggested that sodhana process affects the quantity of guggulsterone E\&Z but do not modify its chemical properties.
\end{abstract}

Keywords: Commiphora wightii, Shodhan Dravya, Sodhana Process

\section{Introduction}

Commiphora genus has approximately 165 species. All species are very slow growing with small thorny, sturdy, highly branched small balsamiferous trees with a short trunk and thin papery bark ${ }^{1}$. Commiphora wightii (Arn.) Bhandari is one of the species which is widely cultivated in rocky tracts of the dry and semi-dry region of India, Pakistan, Bangladesh,

\footnotetext{
${ }^{*}$ Author for correspondence
} 
China, Arabia and Tropical and Northen Africa and many other countries ${ }^{2}$.

In India, it is found in dry, rocky and sandy tracts of Rajasthan, Gujarat, Maharashtra, and Karnataka $^{3-5}$. It is commonly known as "Guggul" or "Indian Bdellium" due to the presence of aromatic steroidal kenotic compounds like guggulsterone E\&Z and its related guggulsterone I-IV ${ }^{6,7}$.

Guggul is oleo-gum-resin obtained from deep incisions at the basal part of stem bark of Commiphora wightii belongs to Burseraceae family. It has a wide range of pharmacological activities including cardiovascular disorders, hypolipidemic ${ }^{8,9}$, antiapoptotic $^{10}$, anti inflammatory ${ }^{11}$, antithyroid ${ }^{12,13}$ and hepatoprotective ${ }^{13}$ along with applications in perfumery and incense industry ${ }^{14}$.

According to the Ayurvedic history, guggul is considered as a God gift. According to Vedas guggul is described as "Agni Sthana" and used for dhupa $^{15}$. Guggul was used externally as well as internally during the period of Charaka (1000 B.C.) and Sushruta (600 B.C). Vagbhata (1700 A.D.) has described the use of guggul as a drug of choice for medoroga and vatavikaras ${ }^{16-19}$.

Some plants and crude drugs obtained from the plant are generally possessed unwanted impurities and toxic substances, which can lead to harmful effect to human body ${ }^{20}$ like Aconite, Nux vomica, Bhillama, Abrus, Datura, etc., these toxic substances should be removed from the raw drugs. All these toxic drugs should be purified and converted into suitable safe dosage forms for therapeutic use. Hence purification is an important step towards their safe, effective and suitable usage. Toxic plants need to be purified by various methods. In Ayurveda, this process is known as sodhana process. The sodhan is divided into two types: 1 . Samanya sodhan and 2. Vishesh sodhan ${ }^{21-23}$.

Ayurvedic Formulary of India recommends the sodhan process of Guggul. Guggul piece is kept on cloth and boiled in Dola Yantra containing any of the sodhan dravya like gomutra, godugdha, Triphala kwath, vasapatra kwath, vasapatra svarasa and nirgundi svarasa with haridra churna. The boiling is continued till the guggul becomes a soft mass. It is then taken out of the cloth and spread over a smooth wooden board smeared with ghee or oil. By pressing with fingers the sand and other remaining foreign impurities are removed, it is taken out and again fried with ghee and ground in a stone mortar (Khalva). This is called as a shodhita guggul.

Another method is to suspend the bundle of guggul in Dola Yantra so as to remain deep in the specified fluid as it is boiled. The boiling of guggul in dola yantra is carried on until all the guggul passes into the fluid through the cloth. The residue in the bundle is discarded. The fluid is filtered and again boiled till it forms a mass. This mass is dried in sun light and then pounded with a pestle in a stone mortar, adding ghee in small quantities till it becomes waxy. This is known as shodhit guggul.

There is also another practice of steaming the 
guggul in vapour by suspending it in the dola yantra without actually immersing it in water.

As per Ayurvedic literature the sodhana process is important for guggul but no literature is available to identify the phytochemical variation in different shodhit guggul and the effect of different sodhan dravya on the chemical properties of guggul.

According to Sanskrit, guggul means "That which protect against disease". Guggul is not considered as a toxic.As guggul is an exudate, unorganized drug having external impurities like dust, stone, debris, dry leaves and other foreign materials, it should be removed. It has been stated in Ayurvedic texts that the raw guggul (unpurified guggul) may lead to headache, diarrhea, anorexia, abdominal pain, skin rashes, irregular menstruation, and mild gastrointestinal discomfort. It produces liver toxicity with very high doses $^{24}$. In order to overcome the side effects of raw guggul; in Ayurveda, guggul is always purified prior to use. It should be purified by two methods; samanya sodhana as well as vishesh sodhana method. Traditionally, Guggul formulations should be prepared with shuddh guggul (purified guggul). It is used as combinations with several herbs to enhance its effects. ${ }^{25}$ Purified guggul reduce toxicity. After purification; it becomes safer and more effective for use. It may be taken for a long time without any side effect.

The exudate material of Commiphora wightii contains a complex mixture of resin (61\%), gum (29.3\%) and other chemicals (6.1\%). More than 150 compounds have been reported and new compounds continue to be reported ${ }^{26}$. Guggul contains several plant sterols, resin, gum, diterpenes, steroids, alcohols and other chemicals, however, its different benefits exist in two main inter-convertible isomeric forms of guggulsterone $\left(\mathrm{C}_{21} \mathrm{H}_{28} \mathrm{O}_{2}\right)$ viz: $\mathrm{E} \& \mathrm{Z}^{27,28}$.

These are responsible for the anticholesterol activity $^{29}$. The amount of guggulsterone E\&Z depends upon the exposer of light, temperature, packaging, duration of storage, climatic conditions under which the plants are grown and the harvesting method $^{30,31}$. The neutral fraction of guggul isolation contains non ketonic (88\%) and a ketonic fraction (12\%). The hypolipidemic activity was found to be related guggulsterone E\&Z (cis- and trans-4, 17(20)-pregnadiene-3, 16-dione) which are present in a ketonic fraction. Pharmacological studies suggested that the pure guggulsterone isomers have marked hypolipidemic activity ${ }^{32-34}$.

Guggulsterone is considered as a biomarker and responsible for the therapeutic effects. The content of guggulsterone in guggul is used as a standard for quality control ${ }^{35}$. Therefore, there is a necessity for reliable and constant quantitative determination of bioactive constituents of Commiphora wightii for pharmacological activity and pharmaceutical applications. Some analytical works were done for the qualitative and quantitative estimation of guggulsterone $\mathrm{E}$ and $\mathrm{Z}$. The RP-HPLC-PDA method was successfully developed and validated for simultaneous quantification of biologically active markers; gallic acid, piperine and guggulsterone present in the Triphala guggul; a polyherbal 
formulation ${ }^{36}$. But no reports are available regarding the qualitative and quantitative estimation of guggulsterone E\&Z in different shodhit guggul.

Traditional medicines are easily available but are complex mixtures of natural substances and are prone to variation and adulteration. Guggul is one of the drug widely used in Ayurvedic polyherbal preparation. Guggul is in high demand and also listed as an endangered medicinal plant by IUCN ${ }^{37}$.

Several analytical methods, available in the literature include liquid chromatography LCMS, HPLC, and high-performance thin layer chromatography methods for the quantification of the above-mentioned markers ${ }^{38-42}$. According to review of literature, no reports were available for simultaneous determination of guggulsterone $\mathrm{E} \& \mathrm{Z}$ in different sodhit guggul. In the present work, we have developed a new, simple, rapid and specific LC-MS method for confirmation of guggulsterone (E\&Z) and HPLC method with simultaneous quantification of guggulsterone $(E \& Z)$ in the different shodhit guggul. This method can be used for the standardization of different shodhit guggul.

\section{Materials and Method}

\subsection{Plant Materials}

Raw Guggul [Commiphora wightii (Arn) Bhandari] was procured from Lallubhai Vrajlal Gandhi, Ayurvedic store, Ahmedabad, Gujarat. The fresh gomutra and godugdha were collected locally from Nadiad. All raw materials required for the preparation of different sodhan dravya; dry course powder of vasaka leaves, triphala powder, fresh leaves of vasaka, nirgundi were collected from the J. S. Ayurveda College, College Road, Nadiad.

\subsection{Chemicals and Reagents}

All the HPLC-grade organic solvents such as methanol, acetic acid, Mili Q water and formic acid were procured from Spectrochem Pvt. Ltd, Mumbai, India. The standard Guggulsterone E \& $\mathrm{Z}$ were procured from Natural RemediesPvt. Ltd, Bangalore, India.

\subsection{Instrumentation}

Liquid chromatographic-mass spectroscopy studies was carried out by the model 8030 -Shimadzu using mass detector (MS) with ion source Electro Spray Ionization (ESI) source equipped with a degasser (DGU-20A5R), pump (DGU-20A5R), autosampler (Shimadzu SIL20AC) and column oven (CTO20AC). Nitrogen was used as nebulizer gas. Argon was used as a collison. The MS detection was done by positive and negative ionization mode with the full scan (m/z 100-400). The results were acquired and compared by using Lab Solution Software 5.53 SP3C.

HPLC (Shimadzu) was performed using Photodiode Array Detector (PDA). The PDA was set by optimizing wavelength to give the best response for all samples at $245 \mathrm{~nm}$ to acquire the chromatogram. The work was done at Department of Pharmaceutical Sciences, Saurashtra University, Rajkot. 
Qualitative and Quantitative Estimation of Guggulsterone E and Z in Different Sodhit Guggul by LC-MS and HPLC Method

\subsection{Method of Preparation of Shodhit Guggul}

For the preparation of shodhit guggul, $100 \mathrm{~g}$ of raw guggul was taken. Guggul contains extraneous matter like sand, stone, bark, wood etc. which were removed from raw guggul manually. Guggul sodhana was done by prutthakaran (separation). The physical impurities present in the drug was removed by this method ${ }^{43-45}$.

Raw guggul was triturated using mortar pastel to make it small and uniform pieces. Subsequently, raw guggul was placed over a piece of cotton cloth which was later tied with thread to loosely wrap the guggul to form a potali like a pouch. The potali was supported by a stainless-steel rod and hanged into extraction vessel (dolayantra) containing 1L of different sodhana dravyas. After ensuring that the potali was completely dipped into the dravya, extraction vessel was heated up to boiling of sodhana dravyas. The temperature was maintained between $70-100{ }^{\circ} \mathrm{C}$ to facilitate solubilization of guggul in sodhan media. This process was continued approximately $2-3 \mathrm{~h}$, until guggul melted. During the process, the potali was pressed by the fingers so that the guggul easily comes out from the potali. When the guggul was completely dissolved, the potali was removed from the media. Then it was subjected to further heating at $60^{\circ} \mathrm{C}$ to obtain thick viscous mass. This concentrated [semisolid] guggul was poured into shallow stainless-steel tray smeared with cow ghee into thin uniform layers and dried under the sun. The dried mass was carefully collected as shuddh guggul or purified guggul. Shuddh guggul was stored in a sterile airtight glass container.
The method of preparation was shown in Figure 1. According to this method, different shodhit guggul was prepared with the help of different sodhan dravya;
1. Gomutra Shodhit Guggul (GMSG),
2. Godugdha Shodhit Guggul (GDSG),
3. Triphala Kwath Shodhit Guggul (TKSG),
4. Vasaka Swaras Shodhit Guggul (VSSG),
5. Vasaka Kwath Shodhit Guggul (VKSG),
6. Nirgundi Shodhit Guggul (NSG), and
7. Water Shodhit Guggul (WSG) ${ }^{46-50}$.

\subsection{Method of Preparation of Dodhan dravya (Liquid Media) used for Purification of Guggul}

Sodhan dravya is a liquid in which raw guggul was purified. Different sodhan dravyas were prepared using different Ayurvedic methods. Their methods of preparations are described below.

\subsubsection{Cow Urine (GMSG)}

Fresh 1L cow urine was collected from a diseasefree cow. Collected fresh cow urine was stored in a sterile container for further use. Urine was filtered for removal of impurities and it was immediately used as sodhan dravya.

\subsubsection{Cow Milk (GDSG)}

Fresh 1L cow milk was collected from disease-free cow. Collected fresh cow milk was stored in a sterile container for further use. Milk was filtered for 
Raw Guggul

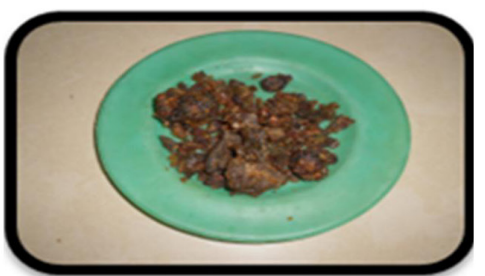

Raw guggul in mortal

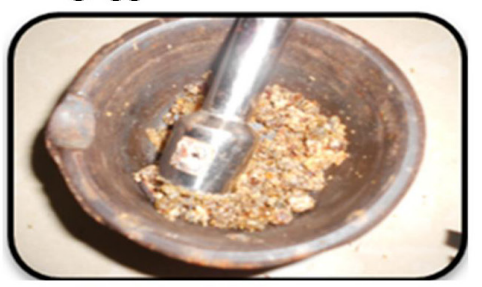

Triturate Guggul

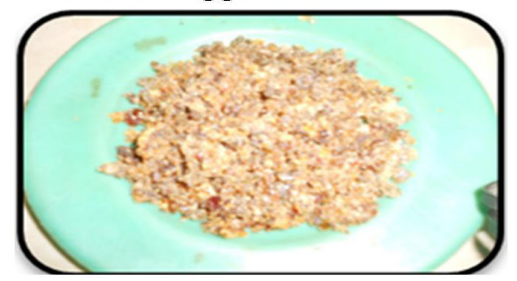

Guggul in Cotton cloth

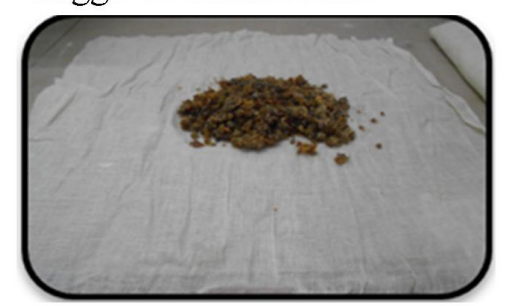

Guggul in Potali

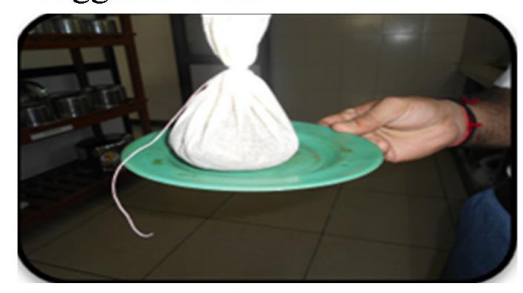

Potali hang in Dola Yantra

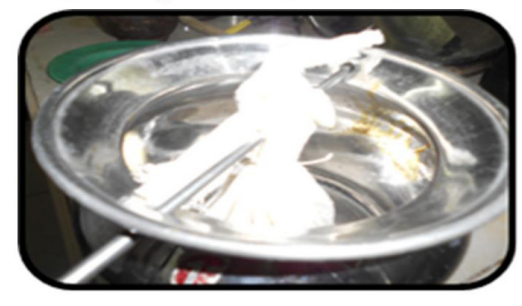

Fig. 1. Preparation Method for Shodhit Guggul
Dola Yantra filled with dravya

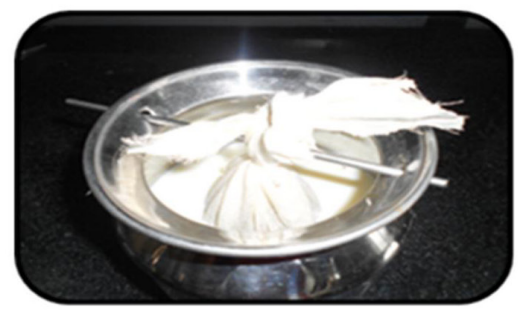

Heating on gas stove

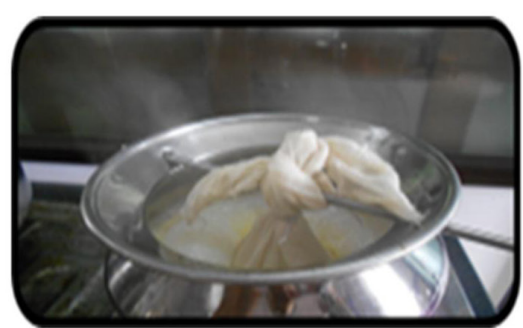

Boil the media untill guggul melt

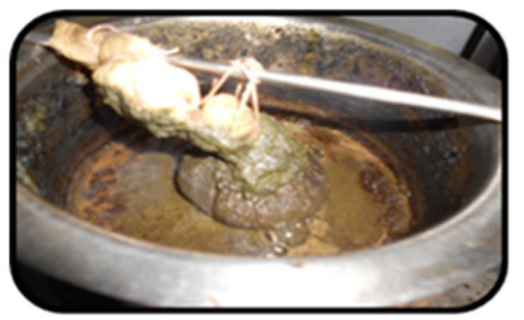

Reduce the volume of dravya

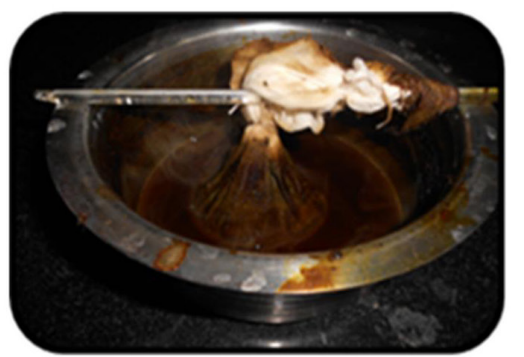

Spread on plate smeared with ghee

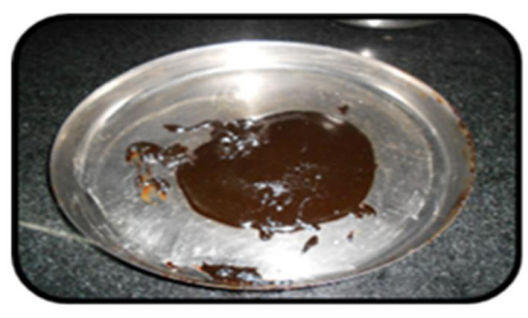


removal of impurities and it was immediately used as dravya.

\subsubsection{Triphala Kwath (Decoction) (TKSG)}

For the preparation of Triphala kwath the coarse powder of haritaki (Terminalia chebula), bibhitak (Terminalia bellerica) and amalaki (Phyllanthus embelica) were taken in equal quantity. $800 \mathrm{~g}$ accurately weighed, coarse powder was transferred to an extraction vessel. Triphala powder was extracted by using $8 \mathrm{~L}$ of water [1part of Triphala powder and 16 parts of water as per classical text]. The resultant mixture was allowed to stand for $12 \mathrm{~h}$. The mixture was boiled till one-fourth of its original volume. The mixture was cooled at room temperature and marc was allowed to settle down. The mixture was filtered. The filtrate was used as

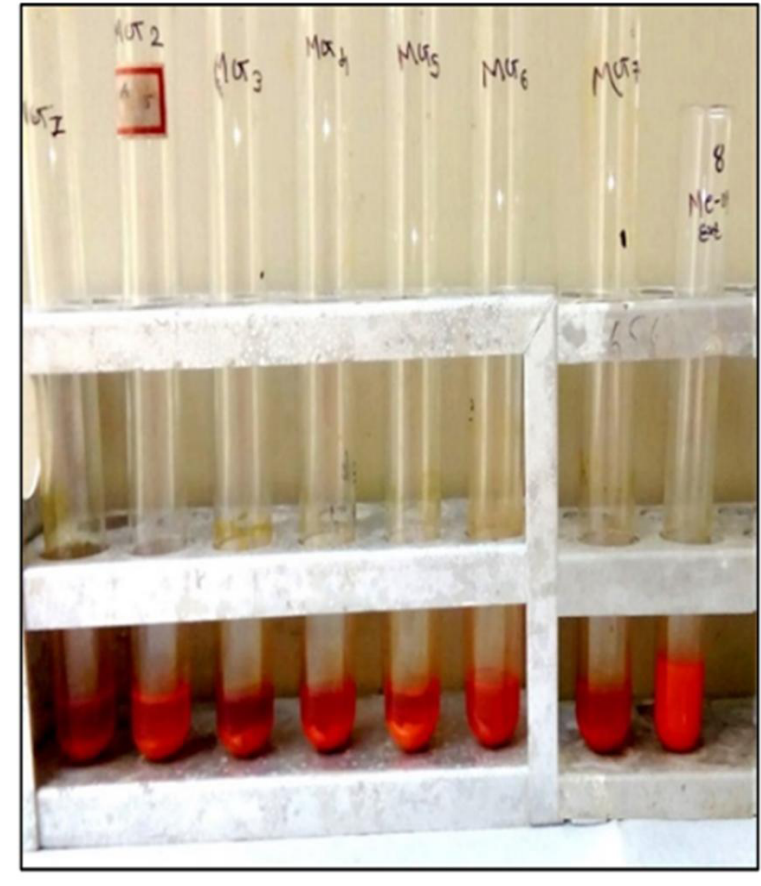

A
Triphala kwath for sodhan process of guggul ${ }^{50}$.

\subsubsection{Vasaka Swaras (VSSG)}

For the preparation of vasaka swaras (fresh leafy juice), $2 \mathrm{~kg}$ of fresh leaves of Adhatoda vasica were collected, washed with water and crushed in a mixture to prepare a slurry. The slurry was filtered to remove impurities and the filtrate was used as sodhan dravya $a^{50}$.

\subsubsection{Vasaka Kwath (Decoction) (VKSG)}

For the preparation of vasaka kwath, $800 \mathrm{~g}$ accurately weighed coarse powder of dried leaves of Adhatoda vasica was transferred to an extraction vessel. The powder was extracted with $8 \mathrm{~L}$ of water [ 1 part of vasaka powder: 16 parts of water]. The resultant mixture was allowed to stand for $12 \mathrm{~h}$. The mixture

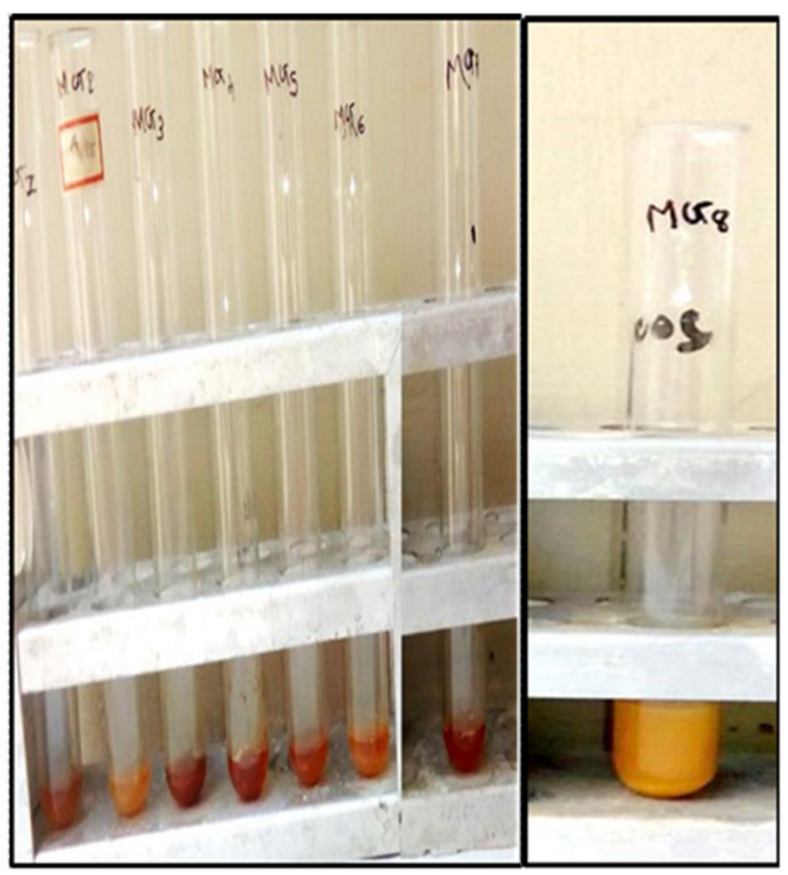

B

Fig. 2. Results of Qualitative Test for Methanolic Extract of Guggul 
was boiled till one-fourth of its original volume. The mixture was cooled at room temperature and marc was allowed to settle down. The mixture was filtered and the filtrate was used as vasaka kwath for sodhan process of guggul ${ }^{50}$.

\subsubsection{Nirgundi Swaras with Haridra Churna (NSG)}

$4 \mathrm{~kg}$ fresh leaves of Vitex negundo were collected, washed with water, cut into small pieces. and soaked in water, for overnight. The slurry was prepared with the help of mixer, small amount of haridra powder was added. It was filtered and the filtrate was used as Nirgundi swaras with haridra churna for sodhana process of guggul ${ }^{50}$.

\subsubsection{Water (WSG)}

Double distilled water was used for purification of raw guggul.

\subsection{Preparation of Samples}

\subsubsection{Preparation of Test Samples}

All impurities of raw guggul like debris, sand, stone etc. were removed. Ten gram of the raw guggul was weighed, transferred to a $100 \mathrm{~mL}$ volumetric flask, $50 \mathrm{~mL}$ of methanol was added and kept for $24 \mathrm{~h}$. The solution was then sonicated for $30 \mathrm{~min}$, at $40^{\circ} \mathrm{C}$, transferred to a centrifuge vial and centrifuged for $20 \mathrm{~min}$ at a $4000 \mathrm{rpm}$, the supernatant liquid was decanted. The same cycle was repeated with 50 $\mathrm{mL}$ of methanol. The extracts were concentrated to a viscous mass at $45^{\circ} \mathrm{C}$ using rotary vacuum evaporator, dried at room temperature and then stored in a refrigerator. These dry samples were reconstituted quantitatively in methanol and used to prepare final concentration $125 \mu \mathrm{g} / \mathrm{mL}$. These test samples were then subjected to analysis.

\subsubsection{Preparation of Stock Solution of Reference Standard}

Standard Guggulsterone E\&Z were purchased from Natural Remedies, Bangalore, India. 10 mg equivalents of guggulsterone $E \& Z$ reference standards were weighed and transferred to a 10 $\mathrm{mL}$ volumetric flask. The volume was then made up with methanol to give $1 \mathrm{mg} / \mathrm{mL}$ solution of each standard. Solutions were stored in deep freeze $\left(-20^{\circ} \mathrm{C}\right)$ and were used within 7 days from the date of preparation. The different concentrations of standard solutions were prepared from the stock solution by different dilutions. The standard stock solutions were further diluted to obtain working standard solutions of different concentrations ranging from 25 to $5000 \mu \mathrm{g} / \mathrm{mL}$.

\subsubsection{Qualitative Test}

The guggul contains guggulsterone E\&Z, which are ketonic constituents; so the qualitative tests were performed for the raw guggul and seven different shodhit guggul. They were identified by performing qualitative tests. Liben's test and 2, 4, DNPH test was performed for all samples.

\subsubsection{Optimization of Chromatography Condition for LC-MS}

The chromatographic separation and identification of guggulsterone E\&Z were carried out using Gemini C18, (150mm x 4.6mm, $5 \mu \mathrm{m})$ column and formic acid in water, $0.1 \% \mathrm{v} / \mathrm{v}$ : methanol, $(25: 75)$ as a mobile phase at the flow rate of $1 \mathrm{~mL} / \mathrm{min},(60 \%$ splitting) coupled with photodiode array detector and Mass Detector (MS). The sample injection volume was $5.0 \mu \mathrm{L}$ with column oven temperature at $40 \pm 0.3^{\circ} \mathrm{C}$. The MS detection was set to ion source Electro Spray Ionization (ESI) in positive 
Qualitative and Quantitative Estimation of Guggulsterone E and Z in Different Sodhit Guggul by LC-MS and HPLC Method

\begin{tabular}{|c|c|c|c|}
\hline S.No. & $\begin{array}{l}\text { Type of shuddh } \\
\text { guggul }\end{array}$ & $\begin{array}{l}\text { Quantity taken } \\
\text { in g } \\
\text { (raw guggul) }\end{array}$ & $\begin{array}{l}\text { Quantity obtained } \\
\text { in percentage } \\
\text { (shodhit guggul) }\end{array}$ \\
\hline 1 & GMSG & 100 & 64 \\
\hline 2 & GDSG & 100 & 147 \\
\hline 3 & TKSG & 100 & 111 \\
\hline 4 & VSSG & 100 & 67 \\
\hline 5 & VKSG & 100 & 64 \\
\hline 6 & NSG & 100 & 83 \\
\hline 7 & WSG & 100 & 75 \\
\hline \multicolumn{4}{|c|}{$\begin{array}{l}\text { GMSG: Gomutra Shodhit Guggul; GDSG: Godugdha Shodhit Guggul; TKSG } \\
\text { Triphala Kwath Shodhit Guggul; VSSG: Vasaka Swaras Shodhit Guggul; VKSG } \\
\text { Vasaka Kwath Shodhit Guggul; NSG: Nirgundi Shodhit Guggul; WSG: Wate } \\
\text { Shodhit Guggul }\end{array}$} \\
\hline
\end{tabular}

and negative ionization mode with the full scan (m/z 100-400). The ion source conditions were set as follows: Temperature, $200{ }^{\circ} \mathrm{C}$; nebulize gas flow, $3.00 \mathrm{~L} / \mathrm{min}$; dry gas flow, $15 \mathrm{~L} / \mathrm{min}$. The experiment was done by optimizing wavelength to give the best response for all samples at $245 \mathrm{~nm}$ to acquire the chromatogram.

\subsubsection{Optimization of Chromatographic Condition for HPLC}

HPLC analysis was done by Gemini C18, (150 $\mathrm{mm} \times 4.6 \mathrm{~mm}, 5 \mu \mathrm{m}$ ) column. The mobile phase was prepared from formic acid in water, $0.1 \% \mathrm{v} / \mathrm{v}$ : methanol, (25:75). The mobile phase was degassed and filtered through a $0.22 \mu$ filter before use. The mobile phase flow rate was kept at $1.000 \mathrm{~mL} / \mathrm{min}$,
(60\% splitting). The sample injection volume was $5.0 \mu \mathrm{L}$ with column oven temperature at $40 \pm 0.3$ ${ }^{\circ} \mathrm{C}$. The auto sampler temperature was $10 \pm 3^{\circ} \mathrm{C}$. The PDA was set by optimizing wavelength to give the best response for all samples at $245 \mathrm{~nm}$ to acquire the chromatogram. The identification of guggulsterone $\mathrm{E}$ and $\mathrm{Z}$ in raw guggul and seven shodhit guggul was done by comparing the RT and spectra of samples with that of reference standards. The chromatograms were acquired and compared by using Lab Solution Software 5.53 SP3C supplied by Shimadzu.

Calibration curves of reference standards were prepared by different concentrations $25 \mu \mathrm{g} / \mathrm{mL}, 50$ $\mu \mathrm{g} / \mathrm{mL}, 100 \mu \mathrm{g} / \mathrm{mL}, 250 \mu \mathrm{g} / \mathrm{mL}, 500 \mu \mathrm{g} / \mathrm{mL}, 2500$ $\mu \mathrm{g} / \mathrm{mL}, 5000 \mu \mathrm{g} / \mathrm{mL}$. It was constructed by plotting 


\begin{tabular}{|l|l|l|}
\hline \multicolumn{3}{|c|}{ Table 2. Percentage weight per weight Guggulsterone E \& Z } \\
\hline Samples & $\begin{array}{l}\text { Total guggulsterone } \\
{[\% \text { w }]}\end{array}$ & $\begin{array}{l}\text { Total guggulsterone in } \\
\text { percentage }\end{array}$ \\
\hline Raw guggul & 1.64768 & 100 \\
\hline GMSG & 1.3687 & 83.06 \\
\hline GDSG & 1.29723 & 78.73 \\
\hline TKSG & 1.22276 & 74.21 \\
\hline VSSG & 1.47176 & 89.32 \\
\hline VKSG & 1.3212 & 80.18 \\
\hline NSG & 1.45029 & 88.02 \\
\hline WSG & 1.58098 & 95.95 \\
\hline $\begin{array}{l}\text { GMSG: Gomutra } \\
\text { TKSG: Triphala Kwath Shodhit Guggul; VSSG: Vasaka Swaras Shodhit } \\
\text { Guggul; VKSG: Vasaka Kwath Shodhit Guggul; NSG: Nirgundi Shodhit } \\
\text { Guggul; WSG: Water Shodhit Guggul }\end{array}$ \\
\hline
\end{tabular}

concentrations against peak area for the respective standards.

\section{Results}

\subsection{Shodhit Guggul}

Raw Guggul was purified by the different sodhit dravyas like gomutra, godugdha, triphala kwath, vasaka swaras, vasaka kwath, nirgundi with haridra churna and water as mentioned in AFI. These methods have also been mentioned in classical text. The $\%$ yields of different shodhit guggul are given in Table 1.

\subsection{Qualitative Test}

The methanol extract of all samples produced orange precipitation with 2, 4 Dinitro phenyl hydrazine and iodoform precipitation with Liben's test. The result is given in Figure 2

\subsection{Quantitative Estimation of Guggulsterone E \& Z using HPLC}

The HPLC analysis of a methanol extract of standard guggulsterone $\mathrm{E}$ and $\mathrm{Z}$ was carried out. Calibration standards were prepared by diluting the suitable volume of stock solution with methanol to get the concentration levels of $25 \mu \mathrm{g} / \mathrm{mL}, 50 \mu \mathrm{g} / \mathrm{mL}, 100$ $\mu \mathrm{g} / \mathrm{mL}, 250 \mu \mathrm{g} / \mathrm{mL}, 500 \mu \mathrm{g} / \mathrm{mL}, 2500 \mu \mathrm{g} / \mathrm{mL}$ and $5000 \mu \mathrm{g} / \mathrm{mL}$. The chromatogram of guggulsterone E showed a peak at retention time $4.9 \mathrm{~min}$ while guggulsterone $\mathrm{Z}$ showed a peak at retention time 

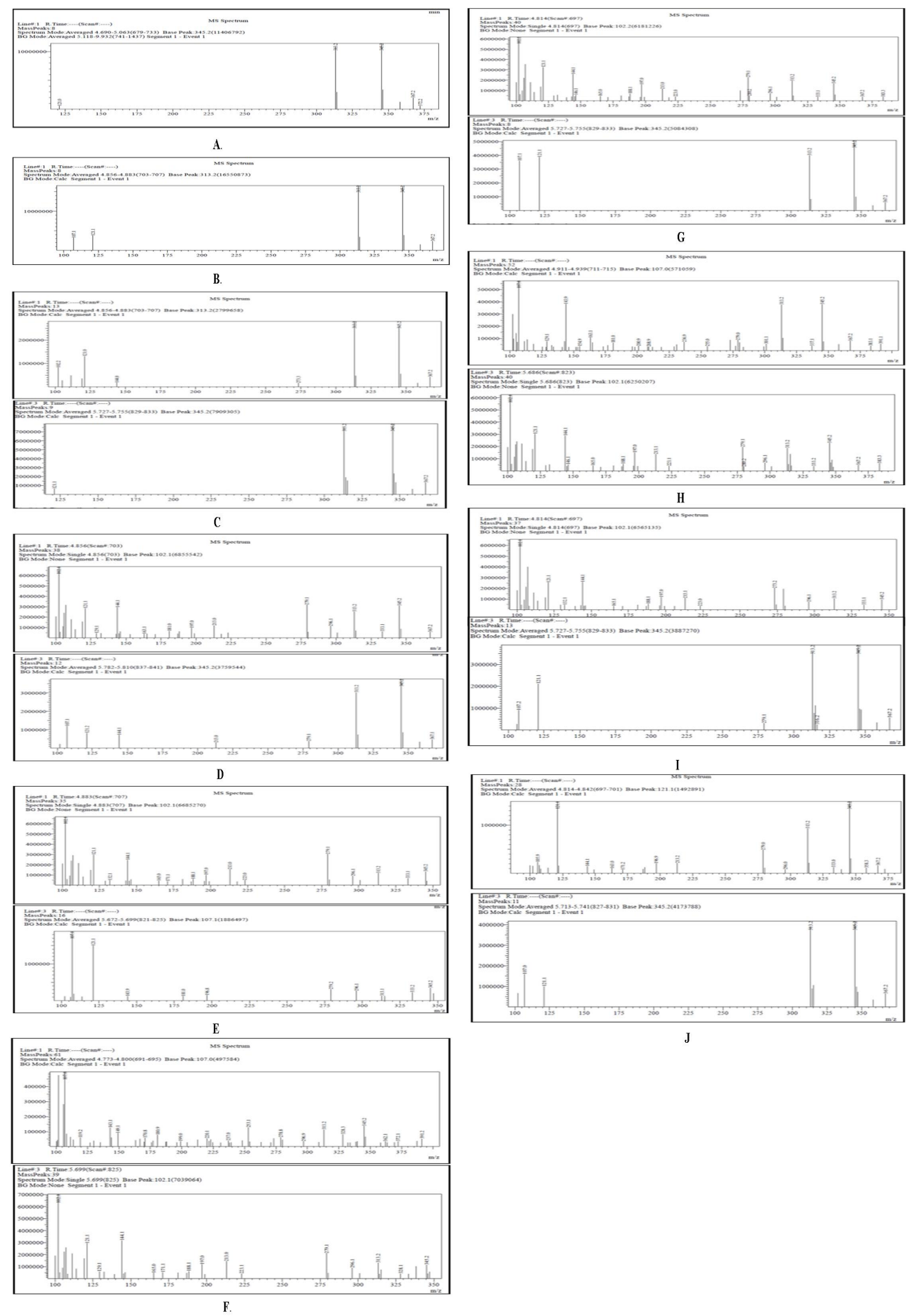

Fig. 3. Mass Spectrum of (A) Guggulsterone E (B) Guggulsterone Z (C) Raw Guggul (D) Gomutra Shodhit Guggul (E) Godugdha Shodhit Guggul (F) Triphala Kwath Shodhit Guggul (G) Vasaka Swaras Shodhit Guggul (H) Vasaka Kwath Shodhit Guggul (I) Mass Spectrum of Nirgundi Swaras Shodhit Guggul (J) Water Shodhit Guggul 


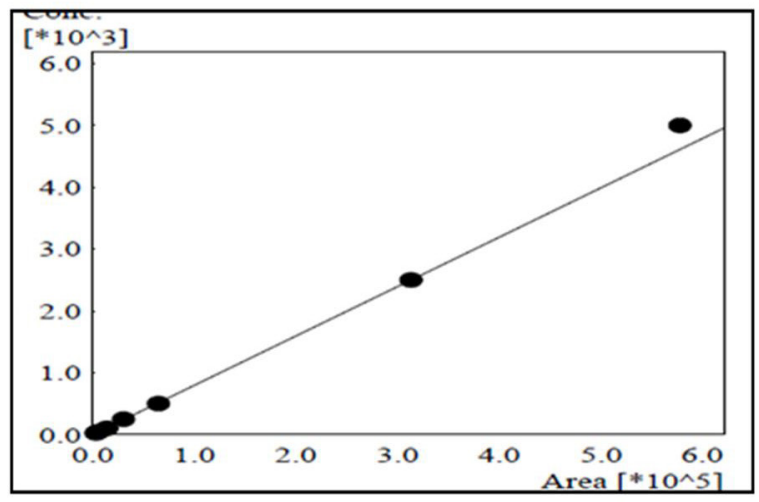

A

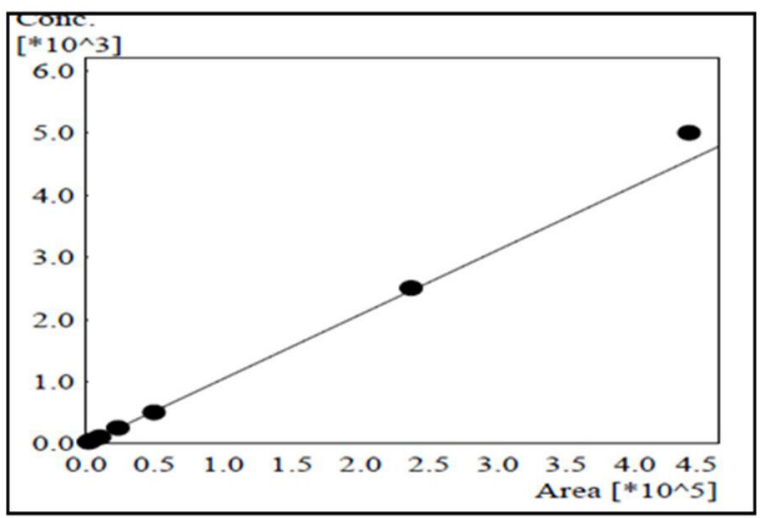

B

Fig. 4. Standard Calibration Curve of (A) Guggulsterone E (B) Guggulsterone Z using HPLC

$5.7 \mathrm{~min}$. The mix standard compound also showed the two main peak at same retention time. The methanol extracts of raw guggul and different shodhit guggul $(125 \mu \mathrm{g} / \mathrm{mL})$ were analyzed by the same method. All samples showed responses at retention time $4.9 \mathrm{~min}$ and $5.8 \mathrm{~min}$, indicating the presence of guggulsterone $\mathrm{E}$ and $\mathrm{Z}$. The quantitative determination was done with the help of calibration curve of both guggulsterone $\mathrm{E}$ and $\mathrm{Z}$. The calibration curve of both the standard drugs was presented in Figure 3. The HPLC chromatograms of standard, raw and different shodhit guggul are shown in Figure 4 . The $\% \mathrm{w} / \mathrm{w}$ of guggulsterone $\mathrm{E}$ and $\mathrm{Z}$ present in raw as well as seven shodhit guggul are depicted in Table 2.

\section{Discussion}

The guggul was purified by different sodhandravyas. They were selected as per AFI guidelines i.e. gomutra, godugdha, triphala kwath, vasaka swaras, vasaka kwath, nirgundi swaras with haridra churna and water. The \% yield of seven shodhit gugguls was different and varies according to the dravya used for the sodhana Table 1 . The godugdha shodhit guggul showed higher \% yield (147 g) while gomutra shodhit and vasaka swaras shodhit guggul showed less \% yield (64 g) than the others. The \% 


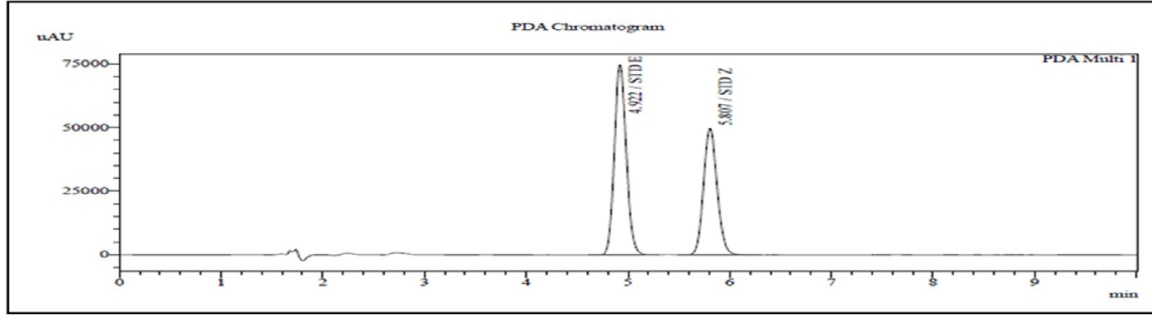

A
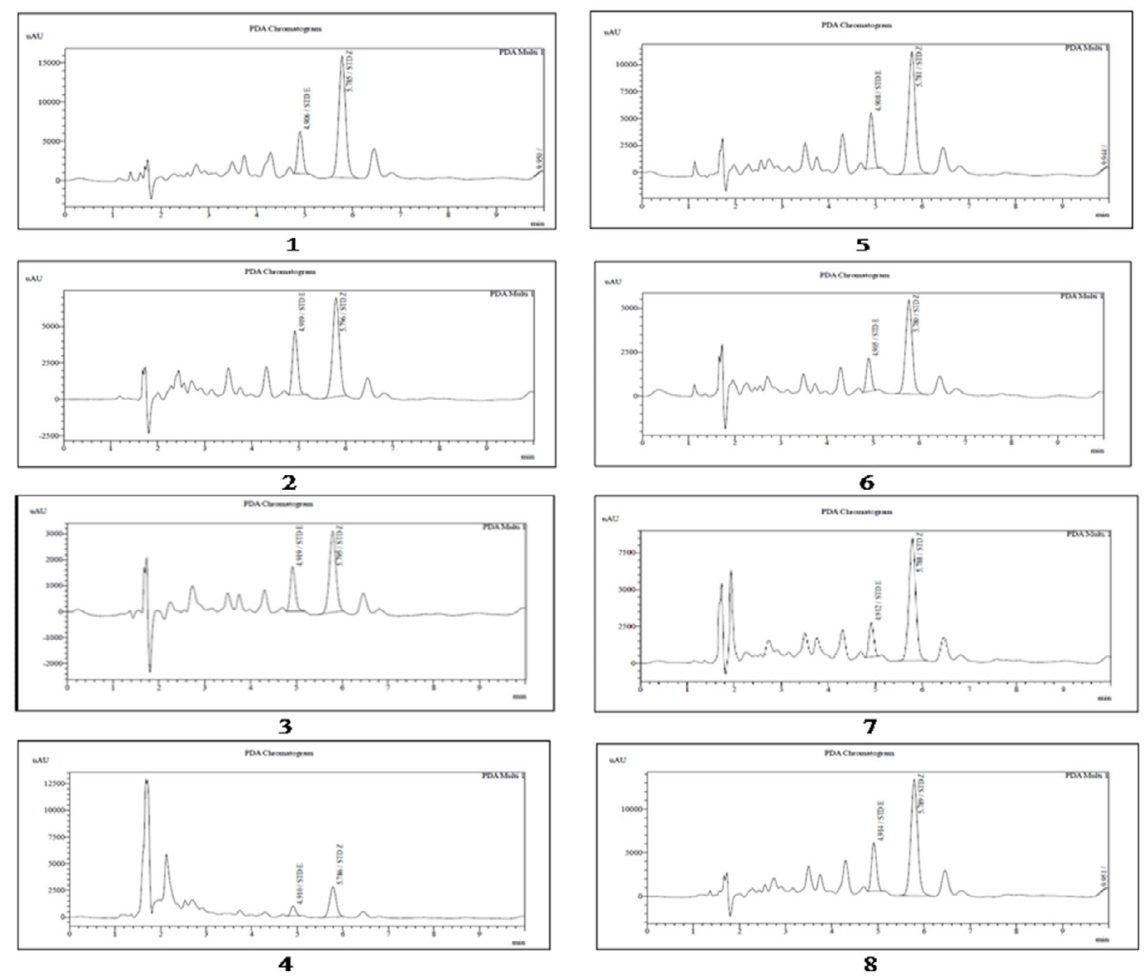

B

Fig. 5. Chromatograms of (A) Guggulsterone E \& Z (Mix Standard) (B) 1. Raw Guggul 2. Gomutra Shodhit Guggul 3. Godugdha Shodhit Guggul 4. Triphala Kwath Shodhit Guggul 5. Vasaka Swaras Shodhit Guggul 6. Vasaka Kwath Shodhit Guggul 7. Mass Spectrum of Nirgundi Swaras Shodhit Guggul 8. Water Shodhit Guggul

yield in case of GDSG and TKSG were higher than raw guggul indicating that there is increase in mass due to addition of sodhana dravya like milk and Triphala kwath. Hence, the overall yield is found more. The \% yield of shodhit guggul was in order Godugdha shodhit guggul > Triphala kwath shodhit guggul > Vasaka kwath shodhit guggul > Nirgundi swaras shodhit $>$ Water shodhit guggul $>$ Vasaka swaras shodhit guggul/Gomutra shodhit guggul.

The methanol extract of raw guggul and seven shodhit guggul indicated positive result with 2 , 4, DNPH and Liben's. The results revealed the 
presence of ketonic compounds in raw guggul and seven sodhit guggul samples. In LC-Ms analysis the chromatograms of reference standards, guggulsterone $\mathrm{E}$, and $\mathrm{Z}$ were obtained at $245 \mathrm{~nm}$ with the retention time $4.8 \mathrm{~min}$ and $5.7 \mathrm{~min}$ respectively (Figure 2). Raw guggul and seven shodhit guggul produced the mass spectrum at this retention time with $\mathrm{m} / \mathrm{z}$ 313.2. This value was similar to the molecular weight of guggulsterone E\&Z. LC-MS study revealed the presence of guggulsterone $\mathrm{E}$ and $\mathrm{Z}$ in raw guggul and seven sodhit guggul.

HPLC method produced highly equal peaks with good resolution standard compounds; Guggulsterone E\&Z at wavelength $245 \mathrm{~nm}$. Guggulsterone E\&Z $(125 \mu \mathrm{g} / \mathrm{mL})$ were satisfactorily determined with retention time 4.8 and 5.7 respectively. A calibration curve was obtained by plotting peak height against the concentration of guggulsterone. The calibration curve of standards was linear in the range of $25-5000 \mu \mathrm{g} / \mathrm{mL}$ (Figure 3 ). The chromatogram of mixed standard is showed in Figure 4.

The chromatograms of all the samples showed peaks at retention time $4.9 \mathrm{~min}$ and $5.7 \mathrm{~min}$, indicating the presence of guggulsterone $\mathrm{E}$ and $\mathrm{Z}$ in all the samples. The amount of guggulsterone E\&Z were calculated from the calibration curve. The raw guggul contained $0.25384 \% \mathrm{w} / \mathrm{w}$ of guggulsterone $\mathrm{E}$ and $1.39384 \% \mathrm{w} / \mathrm{w}$ of guggulsterone $\mathrm{Z}$. The total guggulsterone content was $1.64768 \% \mathrm{w} / \mathrm{w}$ in raw guggul. The total guggulsterone E\&Z content (with respect to that of raw guggul) were found highest in the water sodhit guggul (WSG-95.95\%), while the minimum in Triphala kwath sodhit guggul (TKSG-74.21\%) when compared with raw guggul. The low content in TKSG and GDSG indicated that as the overall mass increased in both cases after sodhana process might be responsible for reduction in content. The guggulsterone content was in order Water sodhit guggul > Vasaka swaras sodhit guggul $>$ Nirgundi swaras sodhit guggul > Gomutra sodhit guggul $>$ Vasaka kwath sodhit guggul $>$ Godugdha sodhit guggul > Triphala kwath sodhit guggul (Table 2). The quantitative estimation by HPLC methods has shown that all samples of sodhit guggul contain a higher amount of Guggulsterone $\mathrm{Z}$ than the Guggulsterone E. It can be concluded that the variation of guggulsterone $\mathrm{E}$ and $\mathrm{Z}$ content in the samples was likely due to the different sodhit dravya used in the sodhana process.

\section{Conclusion}

Optimization of chromatographic conditions is critical for their adequate retention and separation. LC-MS and HPLC is a highly efficient, strong and rapid analytical method for detection and quantification of guggulsterone E\&Z present in raw guggul as well as different sodhit guggul with the best resolution. The study concludes that all sodhit guggul samples contain guggulsterone $\mathrm{E}$ and $\mathrm{Z}$. They did not change chemically. The mass spectra of all samples are same. It indicates the guggulsterone in intact during the sodhana process. It also suggested that sodhana process does not affect the chemical properties of guggulsterone. All sodhit guggul have less content as compared to raw guggul, indicating whatever reduction in the total guggulsterone is due to its solubility in various mediums used for sodhana process. Further, significant variation was found with respect to content of guggulsterone between sodhit and raw guggul. Hence, further preclinical evaluation will only give clarity about effect of sodhan process in its efficacy. 
Qualitative and Quantitative Estimation of Guggulsterone E and Z in Different Sodhit Guggul by LC-MS and HPLC Method

\section{Acknowledgement}

The authors would like to express their thanks and gratitude to Saurashtra University for providing support to analyze all samples. Also thanks to GUJCOST and J. S. Ayurveda College, Nadiad for providing the best research facilities and knowledge about the Ayurvedic method of preparation related to this work.

\section{References}

1. Barve DM, Mehta AR. Clonal propagation of mature elite trees of Commiphora wightii. Plant cell, tissue and organ culture. 1993 Dec 1; 35(3):237-44. Crossref.

2. Kant T, Prajapati S, Parmar AK. Efficient micropropagation from cotyledonary node cultures of Commiphora wightii (Arn.) Bhandari, an endangered medicinally important desert plant. Journal of Plant Development. 2010 Jan 1; 17:37-48.

3. The Ayurvedic Pharmacopoeia of India (Formulations), Department of Indian Systems of Medicine and Homeopathy, Ministry of Health and Family Welfare, Government of India, New Delhi, India; 2007. p. 168-73.

4. Nadkarni KM, editor. [Indian materia medica]; Dr. KM Nadkarni's Indian materia medica: with Ayurvedic, Unani-Tibbi, Siddha, allopathic, homeopathic, naturopathic and home remedies, appendices DNA indexes. Popular Prakashan; 1996. p. 167-70.

5. Sastri BN. The Wealth of India. A Dictionary of Indian Raw Materials and Industrial Products. Raw Materials. The Wealth of India. A Dictionary of Indian Raw Materials and Industrial Products. Raw Materials CSIR Delhi, India; 1950. p. 313-4.

6. Mukherjee PK. Quality control of herbal drugs: An approach to evaluation of botanicals. New Delhi: Horizons Pharmaceutical Publishers; 2002. p. 18693.
7. Regupathi T, Chitra K. Physicochemical analysis of medicinal herbs, Eclipta Alba (L.) Hassk and Lippia nodiflora (Linn.). International Journal of Pharmaceutical and Phytopharmacological Research. 2017 Mar 22; 4(4):249-51.

8. Rajesh P, Latha S, Selvamani P, Kannan VR. Capparis sepiaria Linn-Pharmacognostical standardization and toxicity profile with chemical compounds identification (GC-MS). International Journal of Phytomedicine. 2010 Jan 1; 2(1):71-9.

9. Mulla SK, Swamy P. Preliminary pharmacognostical and phytochemical evaluation of Portulaca quadrifida Linn. International Journal of Pharmtech Research. 2010; 2(3):1699-702.

10. Patnia S, Saha AN. Physicochemical, phytochemical and elemental analysis of stem bark and roots of Berberisasiatica. Adv in App Sci Res. 2012; 3(6):3624-8.

11. Kumar M, Mondal P, Borah S, Mahato K. Physicochemical evaluation, preliminary phytochemical investigation, fluorescence and TLC analysis of leaves of the plant Lasia spinosa (Lour) Thwaites. Int J Pharm Pharm Sci. 2013; 5(2):306-10.

12. Jain SH, Sharma C, Khatri P, Jain A, Vaidya AN. Pharmacognostic and phytochemical investigations of the leaves of Zizyphus xylopyrus (Retz.) Willd. Int J Pharm Pharm Sci. 2011; 3(2):122-5.

13. Panda S, Kar A. Gugulu (Commiphora mukul) induces triiodothyronine production: possible involvement of lipid peroxidation. Life Sciences. 1999 Aug 13; 65(12):137-41. Crossref..

14. Kulhari A, Sheorayan A, Kalia S, Chaudhury A, Kalia RK. Problems, progress and future prospects of improvement of Commiphora wightii (Arn.) Bhandari, an endangered herbal magic, through modern biotechnological tools: a review. Genetic Resources and Crop Evolution. 2012 Aug 1; 59(6):1223-54. Crossref.

15. Pandey MK, Singh GN, Sharma RK, Lata S. Standardization of Yakrit Plihantak Churna: An 
Ayurvedic polyherbal formulation. International Journal of Pharmaceutical Sciences and Research. 2012 Jan 1; 3(1):171-6.

16. Purwantiningsih IP, Santoso D. Identification of standard parameters of kepel leaves [Stelechocarpus burahol (Bl.) Hook. F. \& Th.] and the extract as raw material for anti-hyperuricemic medicaments. Asian Journal of Pharmaceutical and Clinical Research. 2011; 4(1):149-53.

17. Siddiqui MZ. Guggul: an excellent herbal panacea. Asian Journal of Pharmaceutical and Health Sciences. 2011 Jan; 1(1):35-9.

18. Ramawat KG, Marthur M, Dass S, Suthar S. Guggulsterone: A potent natural hypolipidemic agent from Commiphora wightii- Problems, perseverance, and prospects. Bioactive Molecules and Medicinal Plants. 2008: 101-21.

19. Shishodia S, Harikumar KB, Dass S, Ramawat KG, Aggarwal BB. The guggul for chronic diseases: Ancient medicine, modern targets. Anticancer Research. 2008 Nov 1; 28(6A):3647-64. PMid:19189646

20. Maurya SK, Seth A, Laloo D, Singh NK, Gautam DN, Singh AK. Sodhana: An Ayurvedic process for detoxification and modification of therapeutic activities of poisonous medicinal plants. Ancient Science of Life. 2015 Apr; 34(4):188-97. Crossref. PMid:26283803 PMCid:PMC4535066

21. Dikshit M. Poisonous plants as medicine after sodhana: A review. Unique Journal of Ayurvedic and Herbal Medicines. 2016 Mar-Apr; 04(02):1-4.

22. Chaube A, Prajapati PK, Dixit SK. On the technique of sodhana. Ancient Science of life. 1996 Jul; 16(1):6773. PMid:22556773 PMCid:PMC3331135

23. Karan M, Sarup P, Suneja V, Vasisht K. Effect of traditional ayurvedic purification processes (sodhanvidhi) of guggulu on carrageenan-induced paw oedema in rats. Journal of Pharmaceutical and Biomedical Sciences (JPBMS). 2012; 21(21):1-5.
24. Kamble R, Sathaye S, Shah DP. Evaluation of antispasmodic activity of different Sodhit guggul using different sodhan process. Indian Journal of Pharmaceutical Sciences. 2008 May; 70(3):368-72. Crossref. PMid:20046749 PMCid:PMC2792506

25. Taru P, Mukta A, Undale V, Bhosale A. Acute and subacute toxicity studies on sodhana processed guggul. Int J Pharm Sci Res. 2013; 4:796-9.

26. Fatope MO, Al-Burtomani SK, Ochei JO, Abdulnour AO, Al-Kindy SM, Takeda Y. Muscanone: a 3-O(1", 8", 14"-trimethylhexadecanyl) naringenin from Commiphora wightii. Phytochemistry. 2003 Apr 30; 62(8):1251-5. Crossref.

27. Verma N, Singh SK, Gupta RC. Simultaneous determination of the stereoisomers of guggulsterone in serum by high-performance liquid chromatography. Journal of Chromatography B: Biomedical Sciences and Applications. 1998 Apr 24; 708(1):243-8. Crossref.

28. Agrawal H, Kaul N, Paradkar AR, Mahadik KR. HPTLC method for guggulsterone: I. Quantitative determination of E-and Z-guggulsterone in herbal extract and pharmaceutical dosage form. Journal of Pharmaceutical and Biomedical Analysis. 2004 Sep 21; 36(1):33-41. Crossref.

29. Lata S, Saxena KK, Bhasin V, Saxena RS, Kumar A, Srivastava VK. Beneficial effects of Allium sativum, Allium cepa and Commiphora mukul on experimental hyperlipidemia and atherosclerosis-a comparative evaluation. Journal of Postgraduate Medicine. 1991 Jul 1; 37(3):62-8.

30. Agrawal H, Kaul N, Paradkar AR, Mahadik KR. HPTLC method for guggulsterone: II. Stress degradation studies on guggulsterone. Journal of Pharmaceutical and Biomedical Analysis. 2004 Sep 21; 36(1):23-31. Crossref. PMid:15351044

31. Singh S, Manika N, Verma RK, Bagchi GD. Effect of different storage conditions on guggulsterone content in oleo-gum resin of Commiphora wightii. 
Qualitative and Quantitative Estimation of Guggulsterone E and Z in Different Sodhit Guggul by LC-MS and HPLC Method

International Journal of Phytomedicine. 2013 Jan 1; $5(1): 62-8$.

32. Bajaj AG, Dev S. Chemistry of ayurvedic crude drugs- V: Guggulu (resin from Commiphora mukul)- 5 some new steroidal components and, stereochemistry of guggulsterol-I at C-20 and C-22. Tetrahedron. 1982 Jan 1; 38(19):2949-54. Crossref.

33. Dev S. A modern look at an age old Ayurvedic drug Guggul. Science Age. 1987; 5:13-8.

34. Nityanand S, Kapoor NK. Effect of guggul steroids on cholesterol biosynthesis in rats. Indian J Biochem Biophy. 1978; 15:77.

35. Satyavati GV. Gum guggul (Commiphora mukul)The success story of an ancient insight leading to a modern discovery. The Indian Journal of Medical Research. 1988 Apr; 87:327-35. PMid:3049326

36. Muguli GR, Rao VPR, Ramesh B, Gowda V, Paramesh R, Jadhava AN, Babu KS. A novel high performance liquid chromatography-electron spray ionizationmass spectrometry method for simultaneous determination of guggulsterones, piperine and gallica cid in Triphalguggulu. Pcog Mag. 2015 May; 42(11):66-72.

37. Guideline IH. Validation of analytical procedures: Text and methodology Q2 (R1). International Conference on Harmonization; Geneva, Switzerland. 2005. p. 11-12.

38. Basu S, Patel VB, Jana S, Patel H. Liquid chromatography tandem mass spectrometry method (LC-MS/MS) for simultaneous determination of piperine, cinnamic acid and gallic acid in rat plasma using a polarity switch technique. Analytical Methods. 2013; 5(4):967-76. Crossref.

39. Bhatta RS, Kumar D, Chhonker YS, Jain GK. Simultaneous estimation of E-and Z-isomers of guggulsterone in rabbit plasma using liquid chromatography tandem mass spectrometry and its application to pharmacokinetic study. Biomedical
Chromatography. 2011 Sep 1; 25(9):1054-60. Crossref. PMid:21268049

40. Kamal YT, Mohammed Musthaba S, Singh M, Parveen R, Ahmad S, Baboota S, Ali I, Siddiqui KM, Arif Zaidi SM. Development and validation of HPLC method for simultaneous estimation of piperine and guggulsterones in compound Unani formulation (tablets) and a nanoreservoir system. Biomedical Chromatography. 2012 Oct 1; 26(10):1183-90. Crossref. PMid:22213335

41. Musharraf SG, Iqbal N, Gulzar U, Ali A, Choudhary MI. Effective separation and analysis of E- and Z-guggulsterones in Commiphora mukul resin, guggulipid and their pharmaceutical product by high performance thin-layer chromatographydensitometric method. Journal of Pharmaceutical and Biomedical Analysis. 2011 Sep 10; 56(2):240-5. Crossref. PMid:21676570

42. Madhavi GP, Vishal RP, Rakesh KP. Development and validation of improved RP-HPLC method for identification and estimation of ellagic and gallic acid in Triphala churna. International Journal of Chem Tech Research. 2010; 2(3):1486-93.

43. Zhao MH, Shen YP, Liu YJ, Liu GN. Isolated crack in three-dimensional piezoelectric solid. Part II: stress intensity factors for circular crack. Theoretical and Applied Fracture Mechanics. 1997 Mar 1; 26(2):1419. Crossref.

44. Madhavi S and Rani AP. Development and validation of a method for simultaneous determination of dapagliflozin and saxagliptin in a formulation by RPUPLC. World Journal of Pharmaceutical Research; 2017Sep; 12(6):904-16.

45. Chaube A, Prajapati PK, Dixit SK. On the technique of sodhana. Ancient Science of life. 1996 Jul; 16(1):67-73. PMid:22556773 PMCid:PMC3331135

46. Patwardhan B, Mashelkar RA. Traditional medicineinspired approaches to drug discovery: Can Ayurveda 
show the way forward? Drug discovery today. 2009 Aug 31; 14(15):804-11. Crossref. PMid:19477288

47. Anonymous. The Ayurvedic Pharmacopoeia of India. Ministry of Health and Family Welfare Department of AYUSH, Government of India, New Delhi; 1988. p. 56-7.

48. Anonymous. The Ayurvedic Pharmacopoeia of India. Government of India Ministry of Health and Family
Welfare Department of AYUSH, The Controller of Publications Civil Lines, Delhi; 2003. p. 203-24.

49. Anonymous. The Ayurvedic Pharmacopoeia of India Ministry of Health and Family Welfare Department of AYUSH, Government of India, New Delhi; 2007. p. 135-9.

50. Pimpale S, Rao A, Patil A, Desai S. Comparative analytical study of guggul (Commiphora mukul) Sodhana done in different media. Int Ayurvedic Med J. 2014; 2(5):761-4. 